\title{
A spontaneous Pneumocephalus and Hyperpneumatisation of occipital bone and atlas vertebra: a case report.
}

\author{
Sawant $\mathrm{R}^{1}$, Trinidade $\mathrm{A}^{2}$, Das $\mathrm{T}^{3}$ \\ ${ }^{1}$ Ent Department, Addenbrooke's Hospital, Cambridge,UK. \\ ${ }^{2}$ Ent Deparment, Addenbrooke's Hospital, Cambridge,UK. \\ ${ }^{3}$ Radiology Department, Addenbrooke's Hospital, Cambridge,UK.
}

\begin{abstract}
Introduction: Pneumocephalus is the presence of air or gas within cranial cavity. It is caused by craniofacial trauma, tumours of skull base, after neurology or otolaryngology surgeries, occasionally noted in scuba diving and rarely it is spontaneous. Rarely, there can be hyperpneumatisation of skull as well as vertebra which is a rare benign condition can be related to elevated middle ear pressure.

Case Report: A sixty two years old fit and healthy gentleman presented with sudden, severe headache without any history of head injury or surgery. He did not have any focal neurological signs. On Computed Tomography $(C T)$ scan of head, he was found to have pneumocephalus and hyperpneumatisation of occipital bone and atlas vertebra. There wasn't obvious tegmen defect on CT scan. Therefore, Myringotomy and grommet insertion was done to help decompression of pneumocephalus. He improved symptomatically after surgery and analgesia.

Discussion: Spontaneous pneumocephalus is a rare condition. Only twenty four cases are reported with spontaneous onset of pneumocephalus. It should be considered even if there is no focal neural deficit. Hyperpneumatisation of skull and vertebra is a rare condition as well. It is embryological developmental anamaly. There are one hundred and twenty five such cases reported, but only five of them are related with spontaneous peumocephalus. One condition could lead to other, which is discussed only in two articles. Most of the pneumocephalus cases were treated with surgery to repair the dural defect, only two cases were managed conservatively.
\end{abstract}

We have treated our case with minimal surgical intervention to decompress the pneumocephalus.

Keywords: Spontaneous pneumocephalus, hyperpneumatisation of skull and vertebra, middle earpressure, minimal surgical intervention.

\section{Main Article}

\section{Introduction}

Pneumocephalus is the presence of air or gas within the cranial cavity. It is usually associated with head injury, facial trauma, skull base tumours, postoperatively after neurosurgery or otolaryngology surgeries, in some cases of scuba diving. Rarely, it can occur spontaneously. Spontaneous pneumocephalus caused by a primary defect at the temporal bone level without association with pathological conditions is very rare, so far twenty four cases have been reported. Most of the cases were treated surgically except few without neurological deficit, were treated conservatively.

\section{Case report}

We report a sixty two years old gentleman, who presented with sudden onset of headache on bending down. He had rhinitis a week preceding this symptom. He was bending down whilst performing do-it-yourself (DIY) work and suddenly developed severe headache. It was unbearable and wasn't relieved by regular analgesics. There was no history of head trauma, surgery or ear infection. His neurological and otological examination was normal, there was no sinus tenderness. Examination revealed subcutaneous emphysema over his nape of neck. On investigations, his CT scan revealed pneumocephalus and hyperpneumatisation of occipital bone and atlas vertebra. The temporal bone was fluid free and there was no evidence of fracture or tegmen defect.

He was treated with emergency myringotomy and grommet insertion to decompress the pneumocephalus. His symptoms improved significantly after surgery. He was discharged home next day. Two months later he was reviewed in the clinic. During those two months he complained of headache occasionally which was not as severe as before and subsided without any medication. CT scan at follow up visit, revealed complete resolution of pneumocephalus. 
CT Scan imaging:

1a. Pneumocephalus on admission

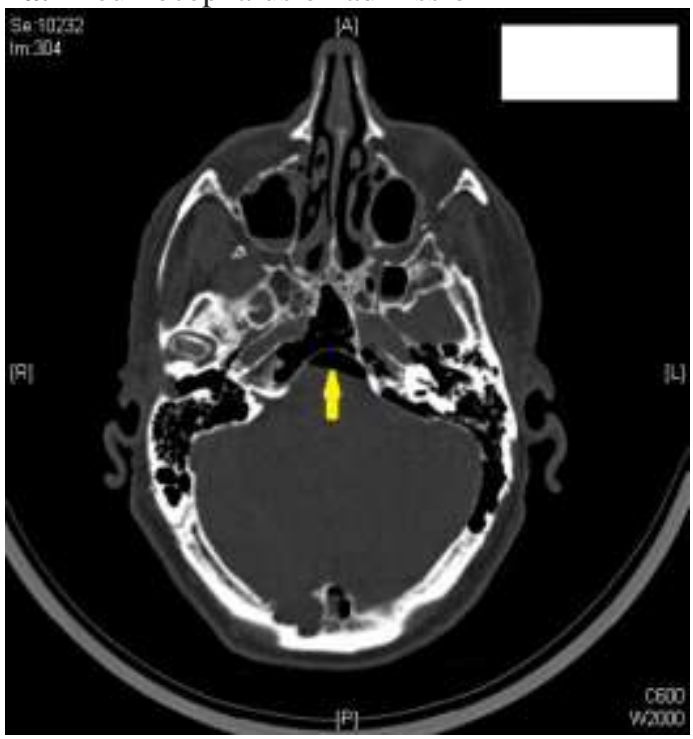

1b.Resolved pneumocephalus at follow up visit

2a. Hyperpneumatisation of Atlas vertebra on admission
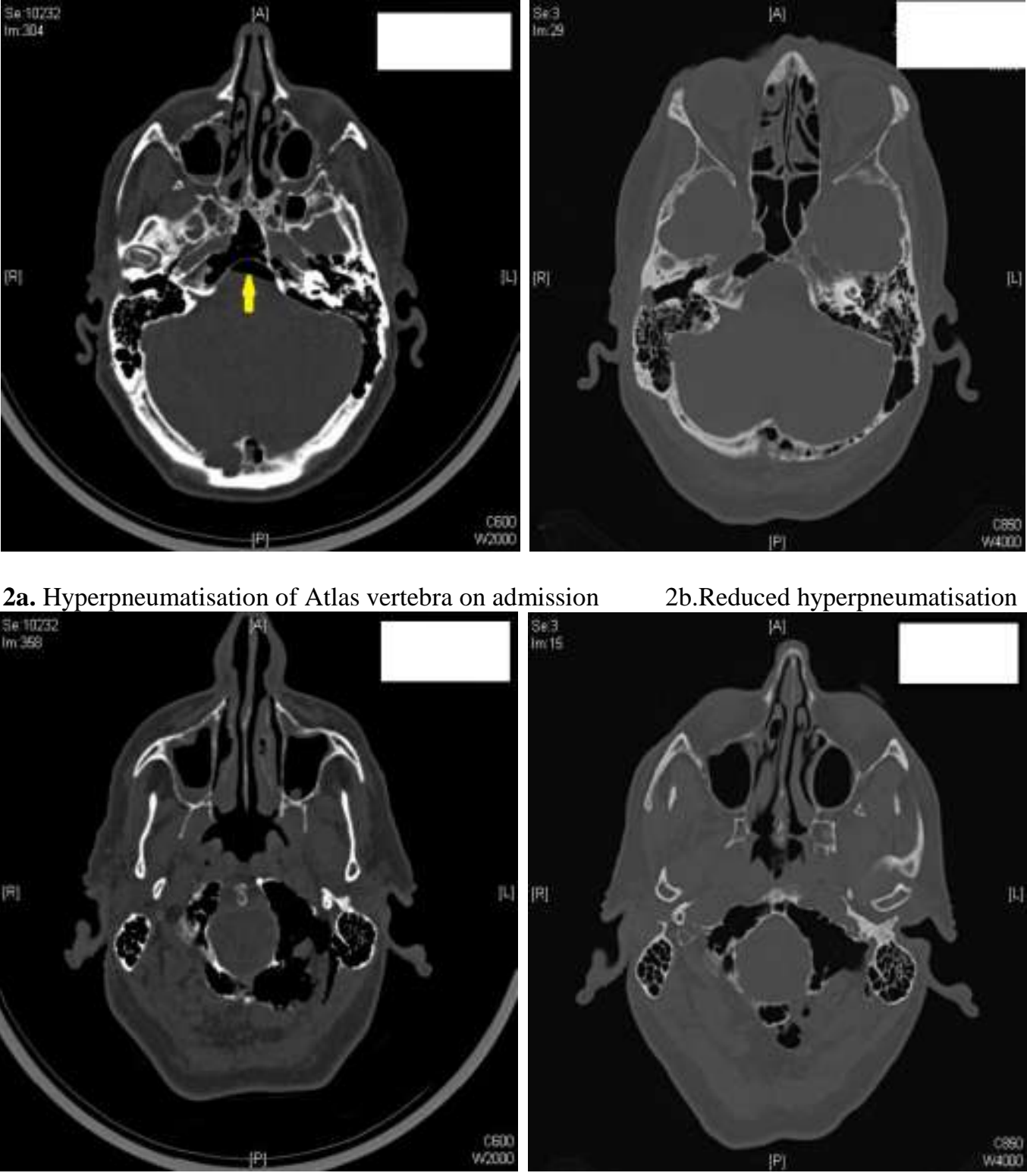

III. Discussion

Pneumocephalus is defined as the presence of air or gas within cranial cavity. The first case report of pneumocephalus was in 1741 by Lecat. $(1,26)$ Its association with craniofacial trauma, neurosurgical or ontological procedures, $(9,14,23,24)$ otomastoiditis,(5) or skull base tumours $(21,27)$ is well known. Spontaneous pneumocephalus caused by a primary defect at the temporal bone level without association with pathological conditions or surgery is very rare.(26,22,28) So far twenty four such cases have been reported. Spontaneous pneumocephalusis accumulation of air intracranially (epidural, subdural, subarachnoid, intraventricular and/or intraparenchymal) without association with craniofacial trauma, ontological or neurological surgery, meningitis, otorhinological infections or skull base tumours.(29)

Out of these twenty four cases, fourteen had extradural pneumocephalus, six were associated with pneumatocele (subperiosteal), five had intraparenchymal pneumocephalus, four with intraventricular and two had subdural pneumocephalus. Six cases presented with more than one location of pneumocephalus.(1,4,8,10,12,15,16,18,20,22,26,28,29) Symptoms: The most common presenting symptom was severe headache. Other symptoms include aural fullness, otalgia, ear crepitations. Some cases presented with otorrhoea, meningeal signs, aphasia, vertigo, facial paralysis, visual changes, vomiting, fainting, paralysis, seizures. Majority of the cases had potential increased middle ear pressure produced by repeated valsalva, nose blowing, change in altitude, chronic cough, diving.(29) 


\section{Mechanism}

For pneumocephalus to occur, a persistent negative intracranial pressure gradient or an extracranial positive pressure sourse is necessary.

1. Inverted soda bottle/Siphon effect: This could be observed in cases with low intracranial pressure due to dural leak or shunt placement, where CSF is replaced by air. $(11,16,20,28)$ Excessive loss of CSF creates a negative pressure gradient, this leads to air entry into intracranial cavity. If the brain substance is tightly adherent to dura at fistula site, air could bypass extracerebral spaces and penetrate the brain directly in the path of least resistance. $(11,29)$

2. Ball valve effect: This can occur in susceptible individuals, those with congenital defects of tegmen tympani or chronic hyperpeumatisation of mastoid air cells. With 'ball valve' effect air could get accumulated intracranially over a period of days to weeks. $(11,12,19,20,26)$

Two pathological conditions must co- exist: A. Defect in temporal bone, B.Gradient of pressure between middle ear and intracranial space to allow the air to enter the cranium.(29) Valsalva's maneuvers or changes in ambient pressure result in passage of high pressure ir through the fistula. This results in increased intracranial pressure which leads to the dura and/or brain to obliterate the fistula, allowing collected air to be trapped. Constantly increased pressure because of Eustachian tube dysfunction or habit of performing Valsalva's maneuvers frequently may lead to hyperpneumatisation.(13) Defects in petrous bone might be common; as per Ahren et al, twenty one percent of autopsy specimens had a single defect and six percent had more than five defects.(2)

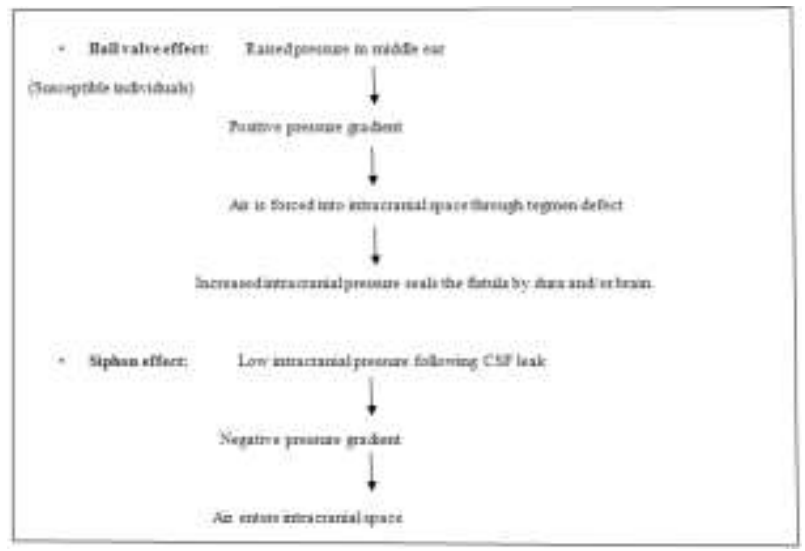

Extradural pneumocephalus could develop if there is progressive separation between the dura and the bone. Nine out of thirteen cases were associated with repeated Valsalva's maneuvers, habit of excessive nose blowing and chronic cough.(29) This condition could also be associated with high- altitude activities such as flying and skiing, in presence of hyperpneumatisation of skull bone.(30) This type of pneumocephalus is more related to persistent trigger factor to force the air intracranially. Intradural pneumocephalus needs a dural defect in addition to bony defect. In only three out of eleven such cases a sudden increase of middle ear pressure led to pneumocephalus. The case reported by Markham had sudden change in altitude.(3) Goldman reported pneumocephalus associated with scuba diving. Singh reported one with Valsalva's maneuver. $(6,25)$ Other possible aetiologies could be minor head trauma in past, history of otomastoiditis, faulty embryogenesis leading to eningoencephalocele which produces arachnoid granulations and adhesions in tegmen tympani.(20.29)

Spontaneous pneumocephalus and hyperpneumatisation of skull bone could be interrelated. One condition could lead to other, which was discussed only in two articles.(15,30) Temporal bone and skull base pneumatisation commences before birth and continues until puberty. This process could vary leading to hyperpneumatisation. As per the skull base maturation process study by Madelaine and Elster, the occipitomastoid synchondrosis of the occipital bone and lambdoid and saggital sutures do not close until the teenage years and third generation, respectively. Patency of these sutures could lead to spread of air and hyperpneumatisation. $(7,30)$ Patients with hyerpneumatised skull base and temporal bone would be more prone to develop spontaneous pneumocephalus with sudden change in pressure gradient.

Treatment of spontaneous pneumocephalus is surgical decompression of accumulated intracranial air and repair the temporal bone defect to seal communication between intracranial and extracranial compartments. Most of the cases were treated by surgical closure of existing fistula using muscle flap, cartilage and bone wax. Cases with recurrence were managed by obliteration of Eustachian tube.(29) Two cases were managed without surgery along with patient education to avoid Valsalva's maneuvers or nose blowing habit to reduce recurrence. $(16,17)$ 
Our case presented with extradural spontaneous pneumocephalus and hyperpneumatisation of basiocciput and atlas vertebra. Hyperpneumatisation could have caused by normal morphological variantion associated with his habit of forceful blowing of nose. Sudden strenuous activity caused positive pressure gradient pushing air forcefully intracranially. As no obvious tegmen defect was noted on CT scan as well as clinically there was no neurological deficit; successful treatment was achieved by surgical placement of tympanic tube.

\section{Conclusion}

- Spontaneous pneumocephalus is very rare.

- This can't be ruled out in absence of neurological signs/symptoms.

- More common in patient with tegmen defect and hyperpneumatisation of skull.

- It is managed by decompressing the intracranial air and repair the tegmen defect.

- Patients with no neurological deficit can be successfully managed either conservatively or by minimal surgical intervention; if no obvious tegmen defect detected.

\section{References}

[1]. Jelsma F, Moore DF. Cranial aerocele. Am J Surg. 1954;87:437-51.

[2]. Ahren C, Thulin CA. Lethal intracranial complication following inflation in the external auditory canal in treatment of serous otitis media and due to defect in the petrous bone.Acta Otolaryngol.1965;60:407-21.

[3]. Markham JW. The clinical features of pneumocephalus based upon a survey of 284 cases with report of 11 additional cases. Acta Neurochir (Wien) 1967;16:1-78.

[4]. Madeira JT, Summers GW. Epidural mastoid pneumatocele.Radiology.1977;122:727-8.

[5]. Andrews JC, Canalis RF. Otogenic pneumocephalus. Laryngoscope. 1986;96:521-8.

[6]. Goldmann RW. Pneumocephalus as a consequence of barotraumas. JAMA.1986;255:3154-6.

[7]. Madelaine LA, Elster AD. Suture closure in the human chondrocranium: CT assessment. Radiology. 1995;196(3):747-756

[8]. Maier W, Fradis M, Schermet R. Spontaneus otogenic pneumocephalus. Ann Otol Rhinol Laryngol. 1996;105:300-2.

[9]. Villarejo F, Carceller F, Alvarez C, Bencosme J, Perez Diaz C, Goldman L, et al. Pneumocephalus after shunting for hydrocephalus. Child Nerv Syst.1998; 14:333-7.

[10]. Park P, Chandler WF, Telian SA, Doran S. Spontaneous chronic epidural pneumocephalus resulting from hyperpneumatization of the cranium causing mass effect: Case report. Neurosurgery. 1998;42:1384-6.

[11]. Dowd GC, Molony TB, Voorhies RM. Spontaneous otogenic pneumocephalus: Case report and review of the literature. J Neurosurg. 1998;89:1036-9.

[12]. Vallejo LA, Gil-Carcedo LM, Borras JM, De Campos JM. Spontaneous pneumocephalus of otogenic origin. Otolaryngol Head Neck Surg. 1999;121:662-5.

[13]. Nyrop M, Bjerre PK, Christensen J, Jorgensen KE. Extensive and symptomatic cranial pneumatization: Caused by frequent performance of Valsalva's manoeuvre? J Laryngol Otol. 1999;113:480-2.

[14]. KannerA, Nageris B, Chaimoff M, Rappaport Z. Spontaneous pneumocephalus in the posterior fossa in a patient with a ventriculoperitoneal shunt: Case report. Neurosurgery. 2000;46:1002-4.

[15]. Añorbe E, Ais P, Saenz de Ormijana J. Spontaneous pneumatocele associated with mastoid hyperpneumatization. Eur J Radiol. 2000;36:158-60

[16]. Schrijver HM, Berendse HW. Pneumocephalus by Valsalva's maneuver. Neurology.2003;60:345-6.

[17]. Bahloul K, Kalamarides M, Bouccara D, Sterkers O, Rey A. Spontaneous otogenic pneumocephalus.

[18]. Neurochirurgie. 2003;49:110-3.

[19]. Richards SD, Saeed SR, Laitt R, Ramsden RT. Hypercellularity of the mastoid as a cause of spontaneous pneumocephalus. J Laryngol Otol. 2004;118:474-6.

[20]. Krayenbuhl N, Alkadhi H, Jung HH, Yonekawa Y. Spontaneous otogenic intracerebral pneumocephalus: Case report and review of the literature. Eur Arch Otorhinolaryngol. 2005;262:135-8.

[21]. Tucker A, Miyake H, Tsuji M, Ukita T, Nishihara K, Ito S, et al. Spontaneous epidural pneumocephalus. Neurol Med Chir (Tokyo) 2008;48:474-8.

[22]. Kamide T, Nakada M, Hayashi Y, Hayashi Y, Uchiyama N, Hamada J. Intraparenchymal pneumocephalus caused by ethmoid sinus osteoma. J Clin Neurosci.2009;16:1487-9.

[23]. Pennings RJ, Liauw L, Cremers CW. A spontaneous otogenic extradural pneumocephalus. Otol Neurotol. 2009;30:864-7.

[24]. Shaikh N, Masood I, Hanssens Y,Louon A, Hafiz A. Tension pneumocephalus as complication of burr-hole drainage of chronic subdural hematoma: A case report. Surg Neurol Int.2010; 1:27.

[25]. Sloan T. The incidence, volume, absorption, and timing of supratentorial pneumocephalus during posterior fossa neurosurgery conducted in the sitting position. J Neurosurg Anesthesiol. 2010;1:59-66.

[26]. Singh A, Alvarez J. Spontaneous otogenic intracerebral pneumocephalus. West J Emerg Med. 2010;11:107.

[27]. Zhao N, Wang DD, Huang X, Karri SK, Wu H, Zheng M. Spontaneous otogenic pneumocephalus presenting with occipital subcutaneous emphysema as primary symptom: Could tension gas cause the destruction of cranial bones? J Neurosurg.

[28]. 2011;115:679-83.

[29]. Guedes Bde V, da Rocha AJ, da Silva CJ, dos Santos AR, Lazarini PR. A rare association of tension pneumocephalus and a large frontoethmoidal osteoma: Imaging features and surgical treatment. J Craniofac Surg. 2011;22:212-3

[30]. Mohammed el R, Profant M. Spontaneous otogenic pneumocephalus. Acta Otolaryngol. 2011;131:670-4.

[31]. Spontaneous intraparenchymal otogenic pneumocephalus: A case report and review of literature.Abbati SG, Torino RR. Surg Neurol Int. 2012;3:32.

[32]. Wemhoff M, Jain R, Rock J. Hyperpneumatisation of the skull Base: Case Report. Neurosurgery 2012;3:E789-94. 